\title{
Dynamic Properties of a Sawn Timber Floor Element with High Transverse Bending Stiffness \\ by
}

Kirsi Salmela and Anders Olsson

Reprinted from

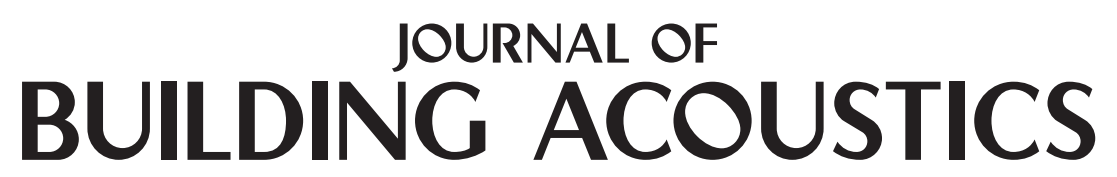

Volume $13 \cdot$ Number $4 \cdot 2006$ 


\title{
Dynamic Properties of a Sawn Timber Floor Element with High Transverse Bending Stiffness
}

\author{
Kirsi Salmela ${ }^{a, b}$, Anders Olsson ${ }^{b}$ \\ ${ }^{a}$ SP Swedish National Testing and Research Institute \\ ${ }^{b}$ Växjö University, School of Technology and Design, Växjö, Sweden \\ akirsi.salmela@sp.se; ${ }^{b}$ anders.olsson@vxu.se
}

(Received 16 June 2006 and accepted 7 September 2006)

\begin{abstract}
A novel wooden floor system for blocks of flats, schools and office buildings where long spans are required is investigated. The floor system aims at high stiffness and good vibration performance. In the longitudinal, main load-bearing direction the floor system works as a truss with flanges of longitudinally oriented timber members and web diagonals of transversely oriented members. In the transverse direction the web diagonals work as beams. A $2.4 \times 4.8 \mathrm{~m}$ floor element with a total height of $260 \mathrm{~mm}$ is examined. Laboratory tests as well as static FE calculations show that the bending stiffness in the transverse direction is of the order of one fourth of the bending stiffness in the main direction. The torsional stiffness is however low. The dynamic properties, i.e. natural frequencies and modes of vibration were evaluated using laboratory tests and FE calculations. In general, laboratory tests and FE calculations were in good agreement. As the study shows promising results, further development and testing are proposed. A test floor is planned in which the transversely oriented wooden members will be replaced by thinwebbed beams of wood and hardboard. In future, the floor will be examined with respect to acoustic properties.
\end{abstract}

\section{INTRODUCTION}

Before the change in building regulations, in the Swedish code, from materialdependent to performance-dependent requirements, the use of timber floors was mainly limited to two-storey residential buildings. Blocks of flats, schools and office buildings were built with concrete-based floor systems. Due to the large mass of concrete and the high transverse stiffness properties of a traditional concrete floor the vibration performance due to human induced vibrations has, in the main, been very good, and users have been accustomed to good vibration performance. Traditional wooden floor systems, in the Nordic countries, consist of joists in the main load-bearing direction and a panel sheathing that is glued and screwed on top of the joists. These structures are characterised by a high bending stiffness in the main load bearing direction and a low stiffness in the transverse direction. The performance with regard to human-induced vibrations is rather poor for long spans. 
In order to improve the vibration properties there are mainly three different methods. The first is to increase the mass, the second is to enhance the stiffness properties and the third is to improve the damping. Increasing the mass by adding concrete or gypsum on top of the floor is commonly used, which at the same time improves the acoustic properties. An improvement in the damping properties may be difficult to achieve using conventional methods. The method that has been shown to have the best effect, however, on the vibration performance of traditional timber floor systems is to increase the transverse stiffness.

In the present paper, the vibration properties of a novel floor structure are studied. It is based on an invention by Mr. Benny Refond but has been modified in cooperation with Växjö University. The main characteristic of the structure is a high transverse bending stiffness, which is vital with regard to good vibration performance.

\section{Description of the floor element}

The concept of the structural design of the novel floor is similar to that of corrugated cardboard and yields high bending stiffness in both the longitudinal and the transverse direction. In the longitudinal, main load-bearing direction, the floor system works as a truss with flanges of longitudinally oriented timber members and web diagonals of transversely oriented timber members, see Figure 1. In the transverse direction of the floor the web diagonals act as beams.

The dimensions of the floor element tested were $2.4 \times 4.8 \mathrm{~m}$ with a total height of $260 \mathrm{~mm}$. The flanges consisted of timber members measuring $45 \times 95 \mathrm{~mm}$, oriented in the longitudinal direction and having a centre-to-centre spacing of $120 \mathrm{~mm}$. The web diagonals consisted of timber members measuring $45 \times 195 \mathrm{~mm}$, oriented in the transverse direction. The timber members were glued and screwed to each other in the contact areas.

At the connections, the diagonals were first screwed together through the glued-on triangular fillets at a centre distance of $150 \mathrm{~mm}$. Then the diagonals were screwed through the triangular fillet into each of the longitudinal members of the bottom flange, at a centre distance of $120 \mathrm{~mm}$, as shown in Figure 2. The top longitudinal members were similarly screwed to the diagonals.

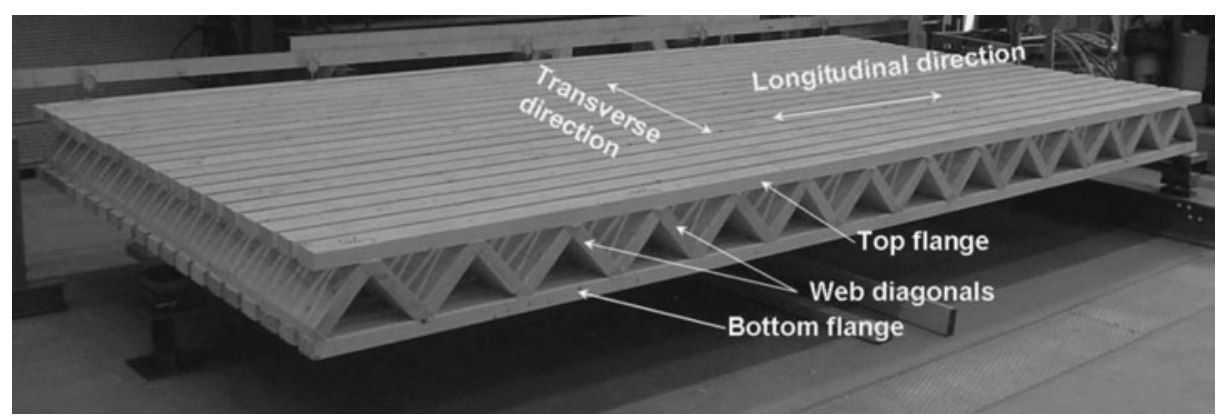

Figure 1. A view of the floor element. 


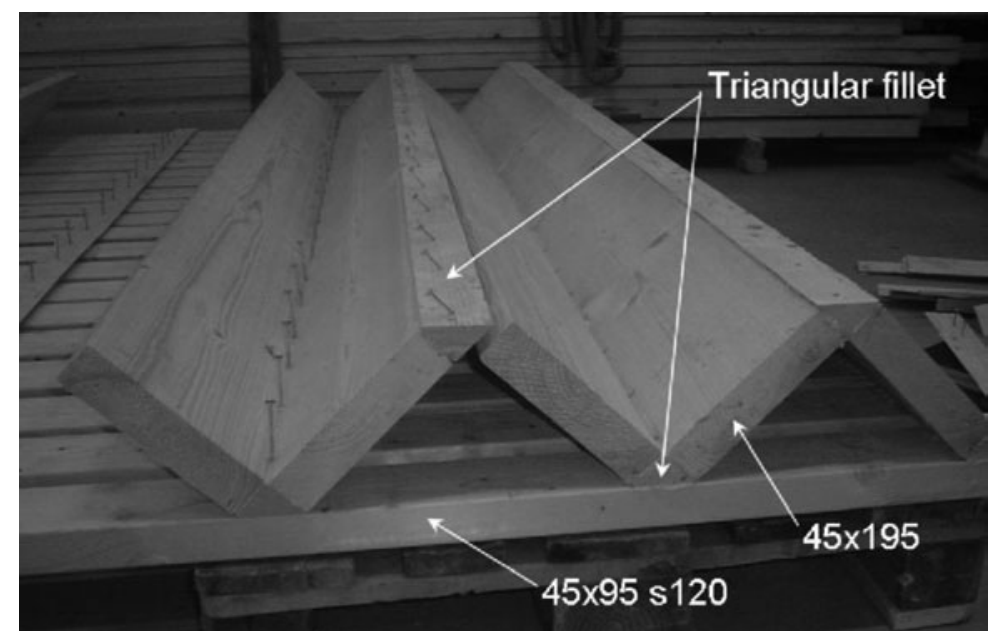

Figure 2. Assembly of timber members.

\section{LABORATORY TESTS}

In order to evaluate the stiffness properties of the floor three static loading tests were performed. An experimental modal analysis was also performed.

\subsection{Static loading tests}

In load cases 1 and 2 the floor element was simply supported along the short sides on two steel beams, placed on the concrete floor in the laboratory. The element was loaded with a $2.3 \mathrm{kN}$ point load, $\mathrm{P}_{1}$, applied at the centre of the floor element, load case 1 , and at the edge of one of the free longitudinal sides, load case 2, as shown in Figure 3.
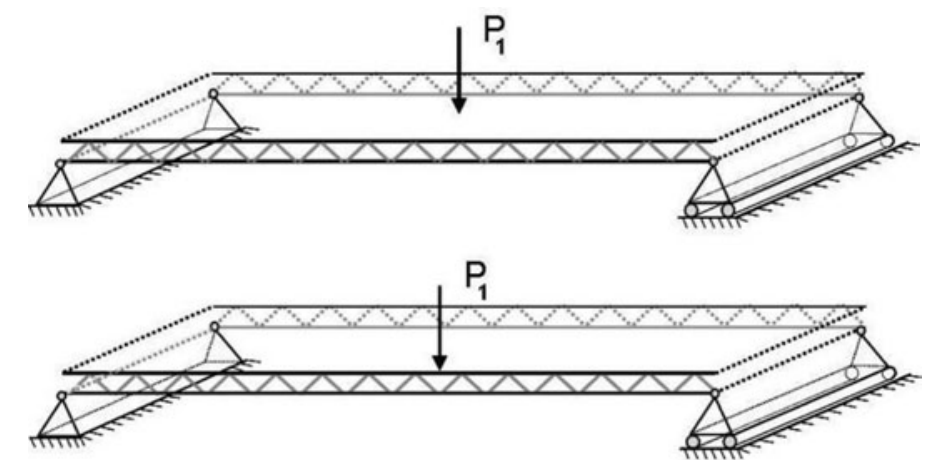

(a) Case 1

(b) Case 2

Figure 3. $\quad$ Support and loading conditions of load cases 1 and 2. 


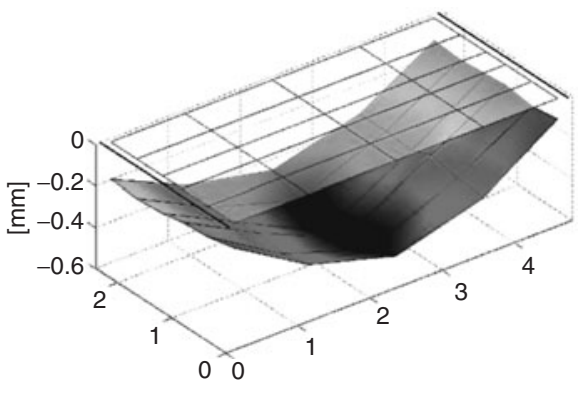

(a) Load case 1

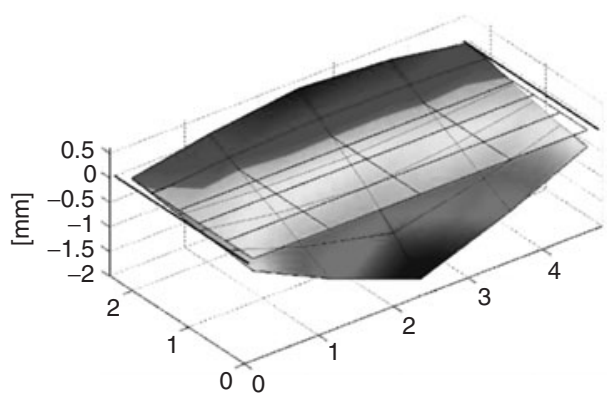

(b) Load case 2

Figure 4. Measured deflection fields of load case 1 and 2.

Before and after the load was applied, the deflections were measured with five dial gauges in a row in the longitudinal direction. To cover the whole surface of the element, measurements were carried out with the five dial gauges placed at six different locations on the element, i.e. they were moved in the transverse direction when the load was off. The tip of each dial gauge was placed on a small piece of plexiglass to level out any irregularities in the surface. The deflections due to the point load, $\mathrm{P}_{1}$, for load case 1 and 2 respectively are shown in Figure 4. (The deflection caused by the weight of the floor is not included.)

The third static loading test, load case 3, was performed to determine the torsional stiffness of the floor element. The element was laid on three support points as shown in Figure 5. At all three supports the rotational degree of freedom was allowed. At one of the corner supports all of the translational degrees of freedom were fixed. At the second corner support the horizontal translation in the longitudinal direction was allowed. At the third support at the centre of the opposite side both the horizontal translations were free.

The element was loaded with a $0.1 \mathrm{kN}$ point load, $\mathrm{P}_{2}$, at one of the free corners as shown in Figure 5. The deflections due to the point load were measured in the same manner as for load cases 1 and 2. The result is shown in Figure 6.

\subsection{Experimental modal analysis}

An experimental modal analysis was performed to derive the natural frequencies, the modal damping and the mode shapes of the floor element. The floor total mass of $640 \mathrm{~kg}$ was calculated as the product of the built-in wood volume and the density of wood,

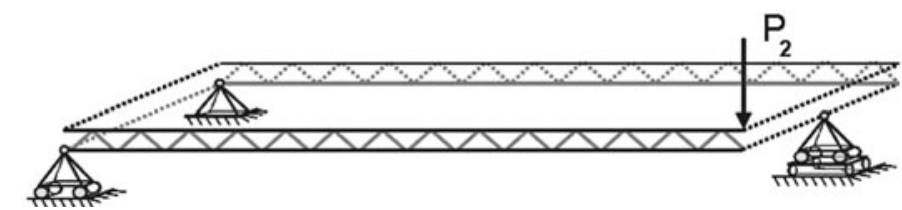

Figure 5. a) Support and loading conditions of load case 3. 


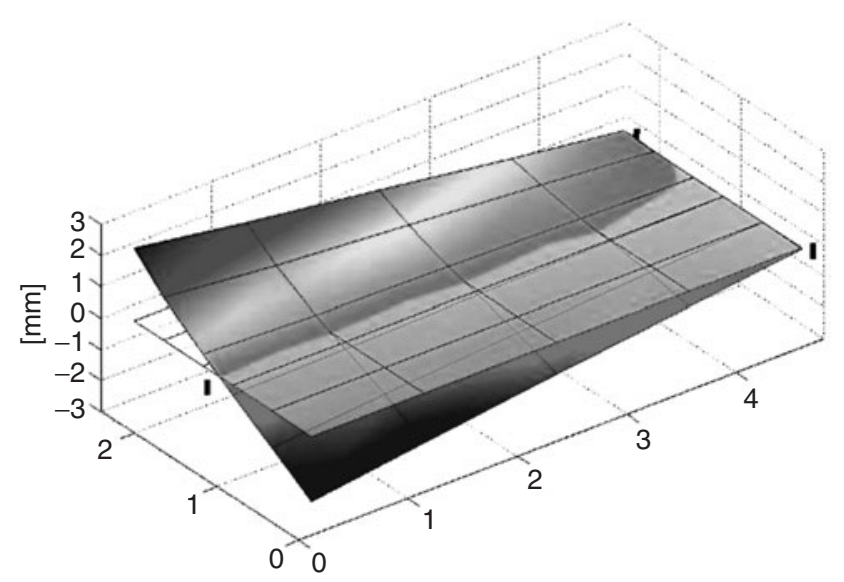

Figure 6. Measured deflection field of load case 3.

which was determined to be $450 \mathrm{~kg} / \mathrm{m}^{3}$. To simulate free-free conditions the element was laid upon two sprung mattresses. A single spring has a stiffness of $169 \mathrm{~N} / \mathrm{m}$ and a mattress consisted of $14 \times 30$ springs held together, but separated in pockets as shown in Figure 7a. The total spring stiffness may be calculated as the sum of all the springs. The two mattresses were placed under the second, third and fourth bottom junction row at each end as shown in Figure $7 \mathrm{~b}$.

The effects of the rigid body modes on the modes of interest may be considered negligible if the frequency of the rigid body mode is less than $1 / 10$ of the lowest frequency of interest. The rigid body modes of the test setup have natural frequencies around $3 \mathrm{~Hz}$. This is too high as regards the first mode of vibration, which is a torsion mode for a plate with free-free support conditions. As it was considered more important to determine the bending modes, the rigid body frequencies were considered sufficiently low.

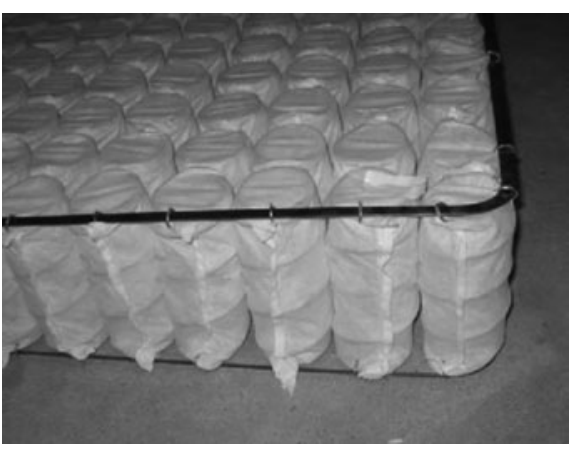

(a)

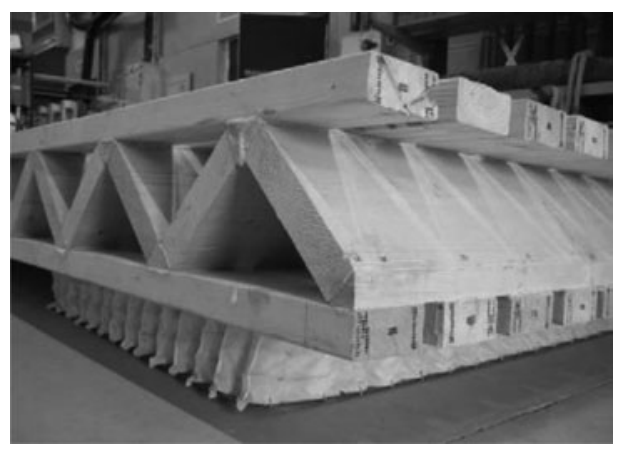

(b)

Figure 7. a) Pocket spring mattress. b) The floor element on sprung mattress. 


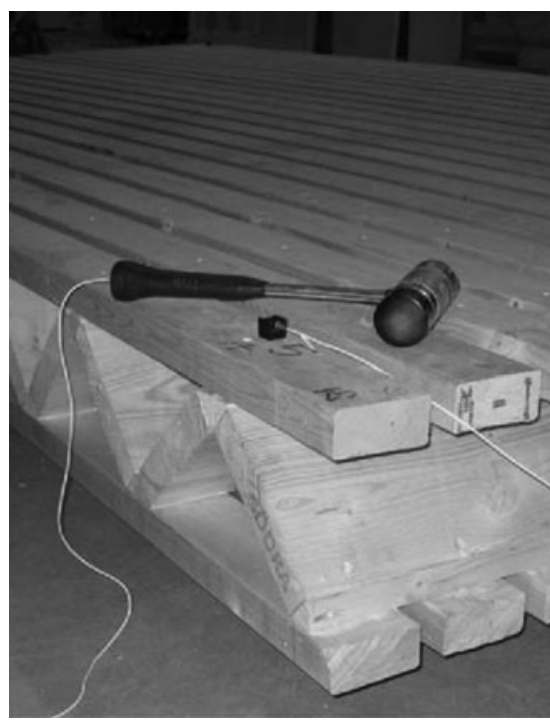

(a)

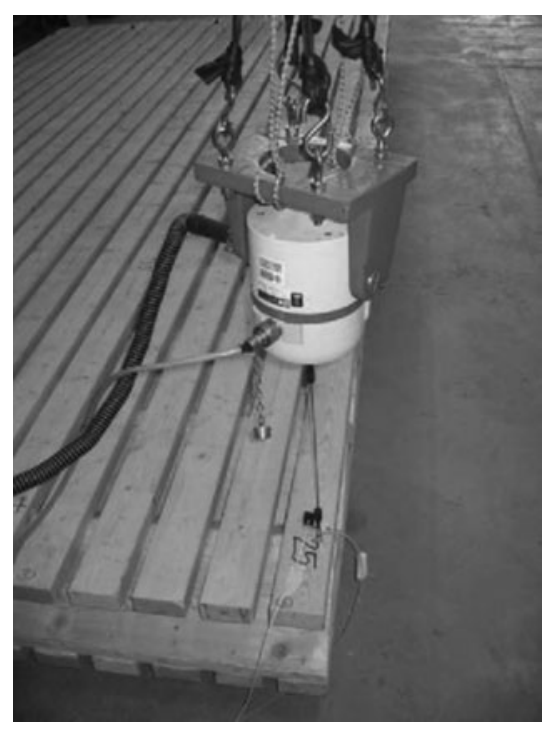

(b)

Figure 8. a) Impact hammer and mounting of an accelerometer. b) Mounting of permanent magnet shaker

The excitation of the structure was achieved both with an impact hammer, Figure 8a, and a permanent magnet shaker, Figure $8 \mathrm{~b}$. The roving hammer technique was used in the modal analysis test and the shaker was used to examine the linearity of the floor element.

The hardest tip on the impact hammer was used to get the highest frequency content possible. The force transducer was mounted on one of the top timber members using an adhesive plate and hot melt adhesive. The transducer was connected to the shaker with a stinger kit. The stinger was chosen to give a frequency content at least as high as that of the impact hammer. The response accelerations were measured with four accelerometers. The accelerometers were mounted with mounting clips and wax on the longitudinal top timber members. The signal analysis was by normal methods [1].

Only the vertical movement of the floor element was studied and the floor element was excited at 25 points on top of the element as shown in Figure 9. Four accelerometers were placed at the corner points numbered 1, 5,21 and 25 .

Since the element possessed low damping and the response signal has to decline within the measurement time to avoid leakage, the length of each measurement was defined by the length of the response signal. The studied frequency range was $600 \mathrm{~Hz}$ and the measurements were performed with 1,600 spectral lines, which gives a measurement time of $2.667 \mathrm{~s}$. Each measurement was obtained from five stable averages and a rectangular window was used for both the force and response signals. The frequency response signals were exported to universal file format for curve fitting $[2,3]$. The frequency response functions of the four accelerometers are shown in Figure 10. 


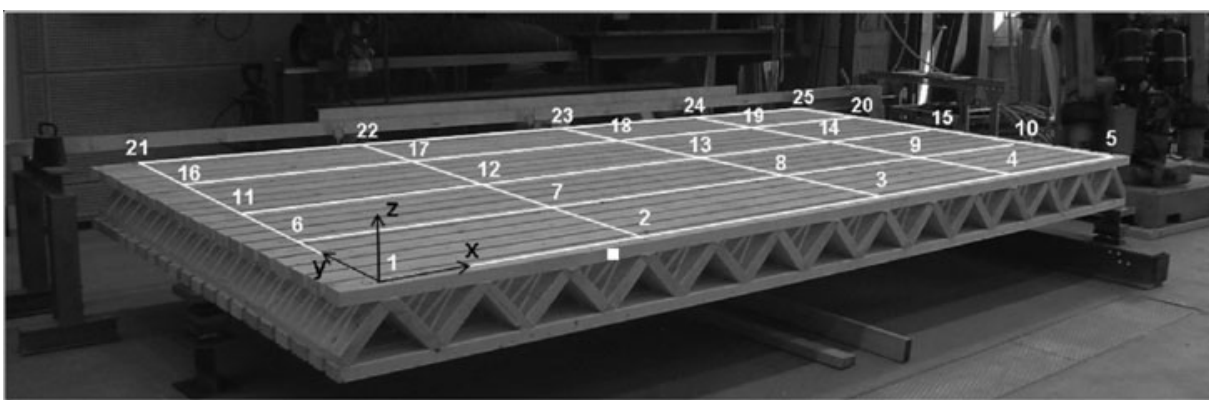

Figure 9. Coordinate system and excitation points.

In Table 1, the first six natural frequencies, that were extracted, are presented together with the corresponding modal damping. The corresponding modes of vibration are presented in Figure 11.

If a structure is linear, the frequency response function is independent of force magnitude. To determine if the floor element possessed linear or non-linear properties, for the force levels considered, it was subjected to a sinusoidal signal with increased force magnitude. The excitation signal was a chirp with frequency content between

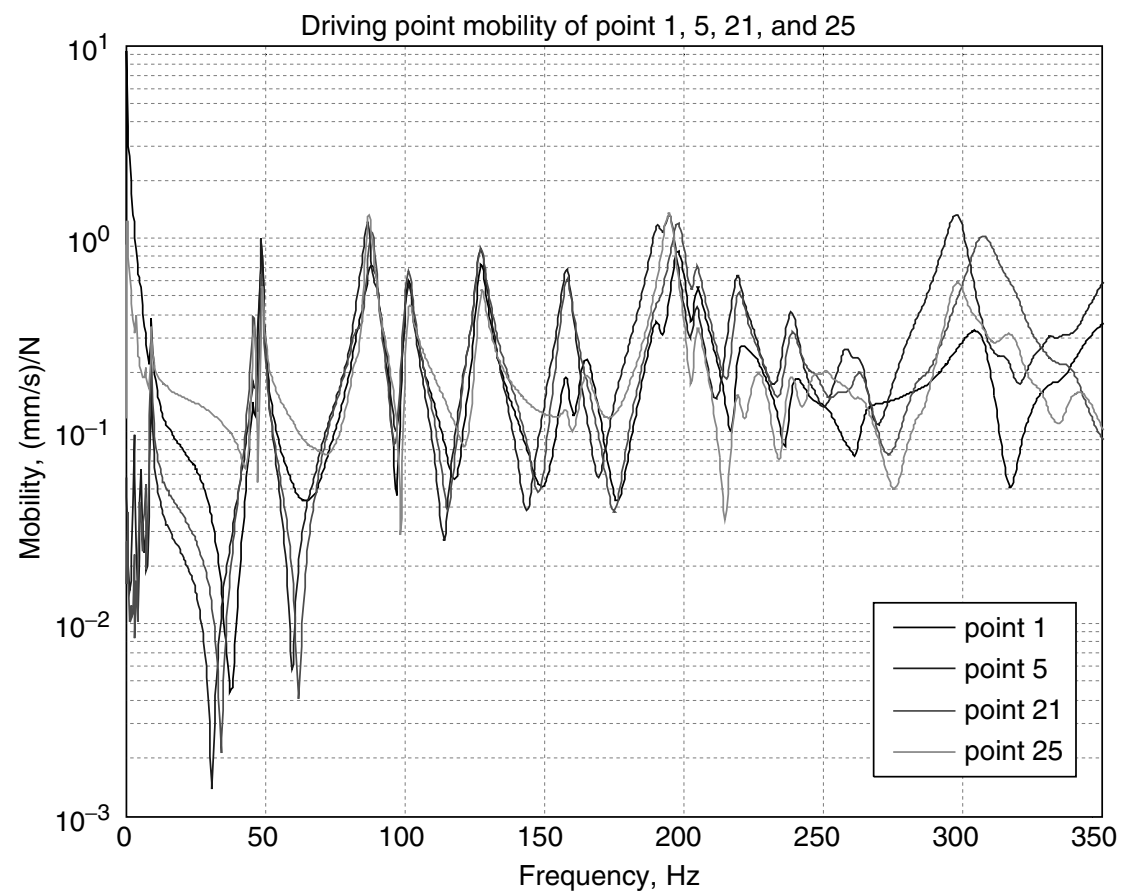

Figure 10. Driving point mobility of reference points. 
Table 1: Natural frequencies and modal damping from the experimental modal analysis.

\begin{tabular}{|c|c|c|c|c|c|c|}
\hline No & 1 & 2 & 3 & 4 & 5 & 6 \\
\hline f $\quad(H z)$ & 9.2 & 46.0 & 48.8 & 87.0 & 88.3 & 101.4 \\
\hline$\zeta \quad(\%)$ & 3.1 & 1.3 & 0.9 & 1.2 & 1.7 & 1.3 \\
\hline
\end{tabular}

0 and $600 \mathrm{~Hz}$. The force magnitude was doubled between the two measurements. The excitation was carried out at point number 25 and the responses were measured at points number 25, 20, 15, 10, 5 and 4. From the frequency response function, in Figure 12, it appears that there are just small deviations in the responses under $300 \mathrm{~Hz}$. This means that the studied structure may be regarded as slightly non-linear in the frequency range of interest.

\section{FEM ANALYSIS}

The floor system is a rather complex 3D-structure. In the present analysis it is assumed however that a finite element model using anisotropic plate elements is sufficient to capture the overall behaviour of the floor when loaded by static loading and to evaluate the dynamic properties of the floor using an eigenvalue analysis. The software employed in the analysis is Matlab ${ }^{\circledR}$ [3] including the FEM toolbox CALFEM [4].

The four-node plate element used to model the floor had three degrees of freedom at each node, one for displacement in the direction perpendicular to the element plane and two rotational degrees of freedom, see Figure 13a. Figure 13b shows the coordinate axes of the floor and the definitions of the moments $M_{x}, M_{y}$, and $M_{x y}$.

Neglecting the Poisson effect, the stiffness properties that must be defined in the plate model are: the bending stiffness in the main and transverse directions of the floor

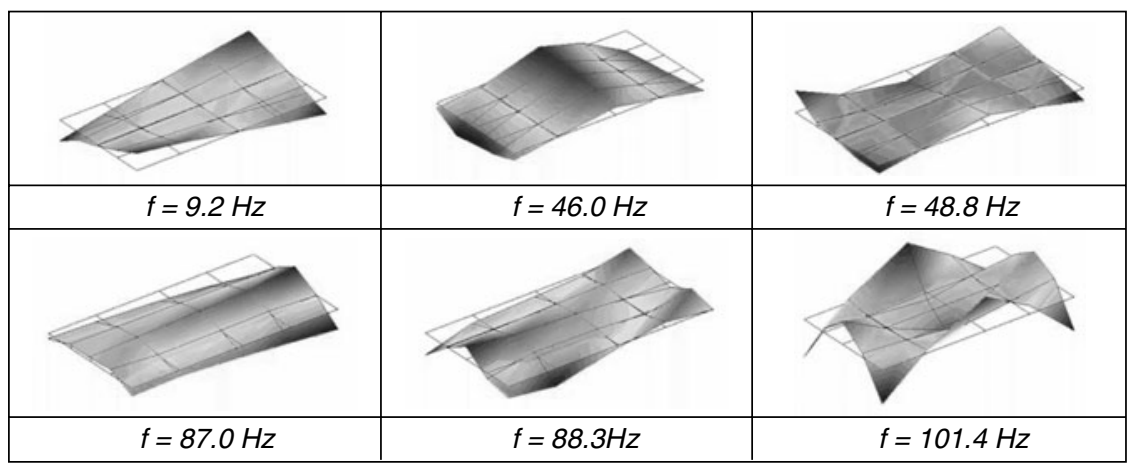

Figure 11. Natural frequencies and modes of vibration from the experimental modal analysis. 


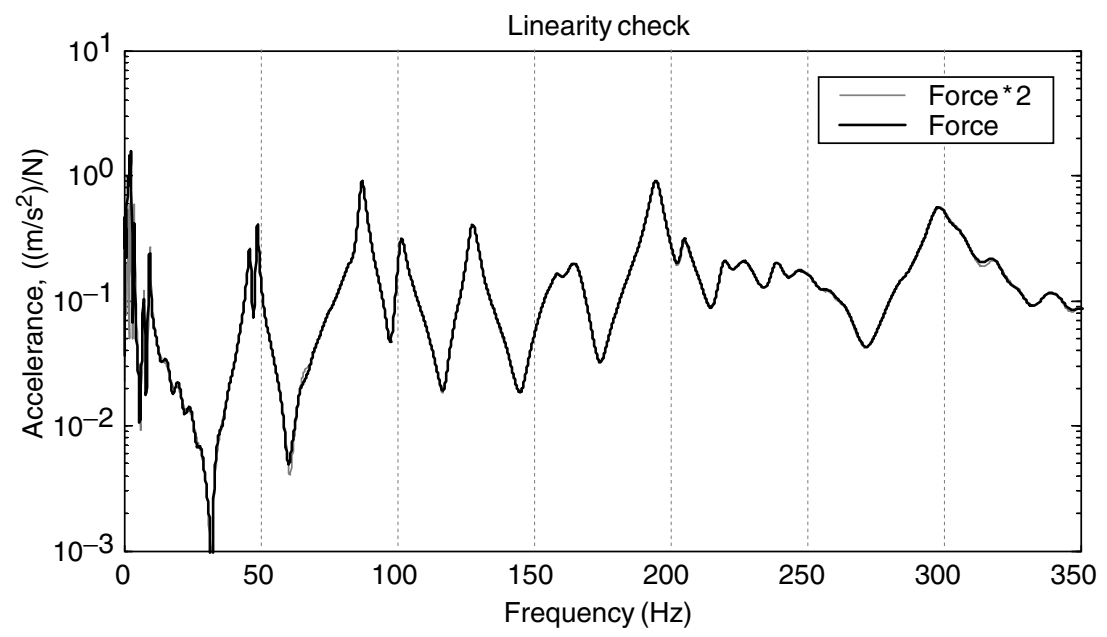

Figure 12. Frequency response functions of chirp signals with increased magnitude.

and the torsional stiffness, $D_{x}, D_{y}$ and $D_{x y}$, respectively. These form the relationship between moments and curvature as follows:

$$
\left[\begin{array}{l}
M_{x} \\
M_{y} \\
M_{x y}
\end{array}\right]=\left[\begin{array}{ccc}
D_{x} & 0 & 0 \\
0 & D_{y} & 0 \\
0 & 0 & D_{x y}
\end{array}\right]\left[\begin{array}{c}
\frac{\partial^{2} w}{\partial x^{2}} \\
\frac{\partial^{2} w}{\partial y^{2}} \\
2 \frac{\partial^{2} w}{\partial x \partial y}
\end{array}\right]
$$
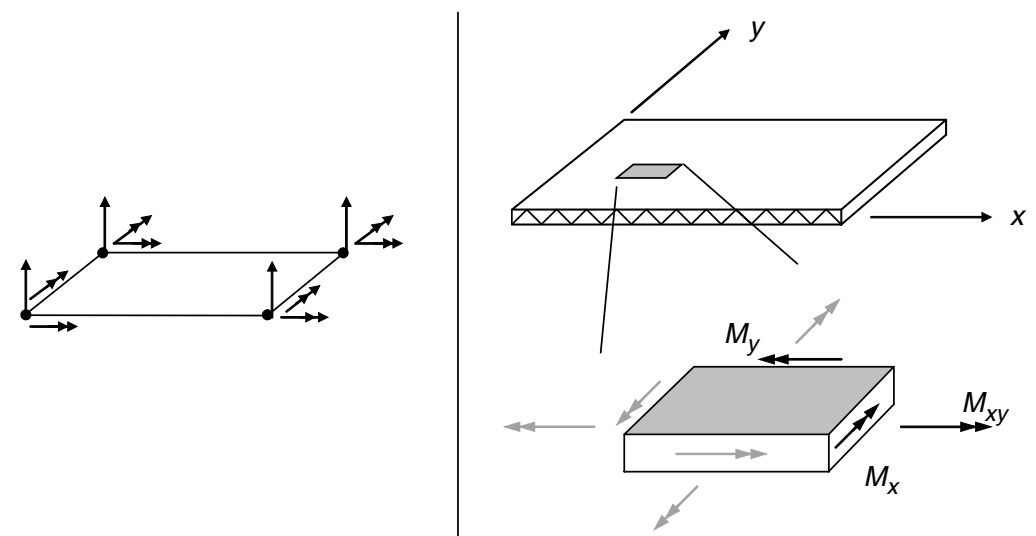

Figure 13. a) Degrees of freedom of the plate element. b) Coordinate axes of the floor and definitions of the moments $\mathrm{M}_{\mathrm{x}}, \mathrm{M}_{\mathrm{y}}$ and $\mathrm{M}_{\mathrm{xy}}$. 
For a solid floor it would now be simple to derive the stiffness parameters knowing the material stiffness values and the thickness of the floor. For the present floor however a combination of calculations and static laboratory tests are necessary for reasonable estimates of the values of $D_{x}, D_{y}$ and $D_{x y}$.

The stiffness in the longitudinal direction, $D_{x}$, of a $1 \mathrm{~m}$ wide and $4.8 \mathrm{~m}$ long strip of the floor in the main direction is calculated using a two-dimensional model of beam and bar elements. In this model the lower and upper horizontal wooden members, oriented in the main direction, were modelled using beam elements coinciding with the centrelines of these members, while the transversely oriented wooden members were modelled by bar elements coinciding with the centrelines of these members. (The offset between the points of intersection of two bar elements and the beam elements is handled by a rigid element.) For the wooden members loaded in the longitudinal direction, Young's modulus was set at $12,000 \mathrm{MPa}$ and for the members loaded perpendicular to the grain, Young's modulus was set at $400 \mathrm{MPa}$. Cross-sectional areas and moments of inertia were set according to the geometry of the floor structure. The boundary conditions of the modelled floor strip were those of a simply supported beam. A point load, $\mathrm{P}$, was applied in the middle of the span. Then the deflection of the middle of the span, $w$, was calculated and the stiffness of the strip, $D_{x}$, was derived as

$$
D_{x}=\frac{P L^{3}}{48 w}
$$

where $\mathrm{L}$ is the length of the span, $4.8 \mathrm{~m}$.

The stiffness in the transverse direction, $D_{y}$, depends on the Young's modulus, $12,000 \mathrm{MPa}$, and the moment of inertia determined by the cross-sectional shape of the members oriented in the transverse direction. $D_{y}$ is then obtained from theYoung's modulus and the moment of inertia for a $1 \mathrm{~m}$ wide strip of the floor in the transverse direction. The influence of the wooden members on the top and bottom of the floor, oriented in the main direction, are neglected when calculating $D_{y}$.

The remaining stiffness, $D_{x y}$, representing the torsional stiffness, would require a more complicated, three-dimensional model to be derived from calculations. Such a model was not developed in the present study. Instead the laboratory test on the floor in load case 3, mainly involving torsion, is used to determine this parameter. As the other stiffness parameters, $D_{x}$, and $D_{y}$, are already determined, the plate-element model is now established. For the parameter $D_{x y}$ the value giving the best fit to the laboratory test on the floor, load case 3 , should be chosen. The criterion for best fit must first be defined, however, and this is done in the following way. A polynomial expression, including only the terms $[1, \mathrm{x}, \mathrm{y}, \mathrm{xy}]$ were fitted (least square sum of residuals) to the measured deflections. Then the value of $D_{x y}$ giving the same calculated deflection in the position of the point load as the deflection according to the polynomial expression representing the measured deflection, is used for $D_{x y}$. The calculated and measured deflections are shown in Figure 14. 


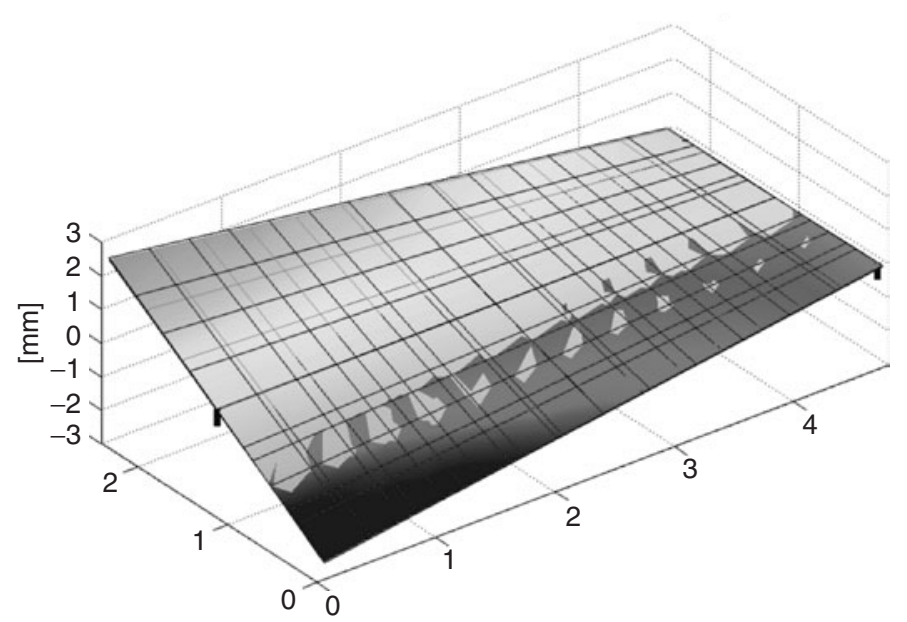

Figure 14. Calculated and measured deflections for load case 3.

The coloured surface represents the FE calculation and the white transparent surface represents the polynomial approximation of the measured deflections. The FE calculation of the deflections was performed with the floor divided into $8 \times 14$ elements. The approximations and calculations described above and the evaluation of the laboratory test (load case 3 ) resulted in the stiffness parameters, are presented in Table 2.

For verification, load cases 1 and 2, which were not employed for determining the stiffness parameters, were simulated using the FE model. Figure 15 shows, for load case 1 and 2 respectively, the calculated and measured deflection fields. The coloured surface represents the FE calculation and the white transparent surface represents the polynomial approximation of the measured deflections. Some rigid body motion of the floor, and also some pure torsion, appears in the laboratory tests of load case 1 and 2 as the result of lack of rigidity of the supports. These rigid body motions and torsional deformations are, however, filtered out and are not included in the deflection fields presented in Figure 15.

For load case 1 the calculated deflection field is in fair agreement with the measured deflections. The deflection in the middle of the floor, where the point load is applied, differs by $11 \%$. For load case 2 the measured deflections differ by $13 \%$ at the position where the point load is applied.

Table 2: Estimated stiffness parameters.

\begin{tabular}{lll}
\hline $\mathbf{D}_{\mathbf{x}}\left(\mathbf{N m}^{2}\right)$ & $\mathbf{D}_{\mathbf{y}}\left(\mathbf{N m}^{2}\right)$ & $\mathbf{D}_{\mathbf{x y}}\left(\mathbf{N m}^{2}\right)$ \\
\hline $6.59 \cdot 10^{6}$ & $1.43 \cdot 10^{6}$ & $2.78 \cdot 10^{4}$ \\
\hline
\end{tabular}




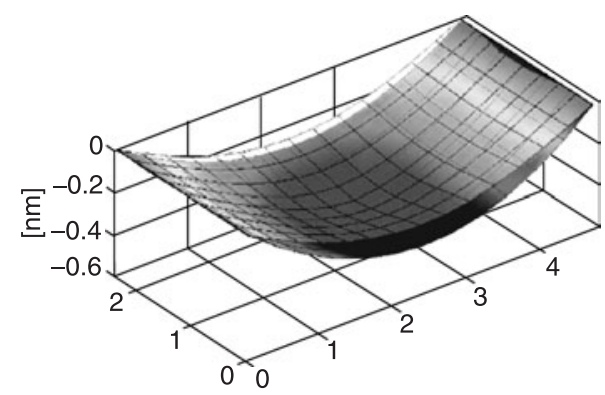

(a) Load case 1

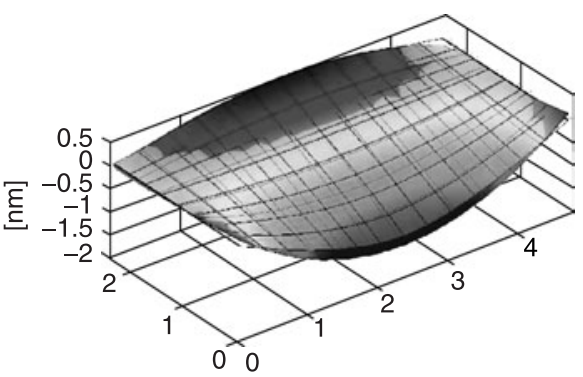

(b) Load case 2

Figure 15. Calculated and measured deflections of load case 1 and 2, respectively.

Using load case 1 , updated values for $D_{x}$ and $D_{y}$ were now derived by fitting these stiffness parameters from the FEM calculations to give deflections coinciding with those from the laboratory test. The deflections under the point load and at the middle of the free long edge were used as criteria for the best fit of the FE model. (The $D_{x y}$ value was not changed.) The new fit values, used in the dynamic calculations, are presented in Table 3.

The $D_{x}$ value was decreased by the fitting procedure by $11.6 \%$ and the value of $D_{y}$ increased by $4.6 \%$. After fitting, the difference between the measured and calculated deflections in the middle of the floor, under the point load and at the free long edge, were $0.17 \%$ and $0.12 \%$, respectively. For load case 2 the deflection field was also improved and the difference in deflection at the point load was decreased to $4.8 \%$.

To evaluate the dynamic properties, i.e. the natural frequencies and modes of the floor element, an eigenvalue analysis was performed. The eigenvalues and modes are extracted by solving the eigenvalue equation

$$
\left|\mathbf{K}-\lambda_{\mathrm{i}} \mathbf{M}\right|=0
$$

where $\mathbf{M}$ and $\mathbf{K}$ are the square mass and stiffness matrices. In the analysis, a lumped mass matrix was used. The same number of elements, $8 \times 14$, was used for the eigenvalue analysis as in the previous simulations concerning static behaviour. The eigenvalues, $\lambda_{i}$, give the natural frequencies as

Table 3: Fitted stiffness parameters.

\begin{tabular}{lll}
\hline $\mathbf{D}_{\mathbf{x}}\left(\mathbf{N m}^{2}\right)$ & $\mathbf{D}_{\mathbf{y}}\left(\mathbf{N m}^{2}\right)$ & $\mathbf{D}_{\mathbf{x y}}\left(\mathbf{N m}^{2}\right)$ \\
\hline $5.82 \cdot 10^{6}$ & $1.50 \cdot 10^{6}$ & $2.78 \cdot 10^{4}$ \\
\hline
\end{tabular}


Table 4: Calculated natural frequencies and frequencies extracted from laboratory tests.

\begin{tabular}{lcccccc}
\hline No & $\mathbf{1}$ & $\mathbf{2}$ & $\mathbf{3}$ & $\mathbf{4}$ & $\mathbf{5}$ & $\mathbf{6}$ \\
\hline $\mathrm{f}_{\mathrm{FEM}}(\mathrm{Hz})$ & 7.4 & 51.9 & 53.3 & 97.2 & 97.8 & 111.0 \\
$\mathrm{~F}_{\text {Lab }}(\mathrm{Hz})$ & 9.2 & 46.0 & 48.8 & 87.1 & 88.3 & 101.4 \\
\hline
\end{tabular}

$$
\mathrm{f}_{\mathrm{i}}=\frac{\lambda_{\mathrm{i}}}{2 \pi}
$$

The corresponding modes are given by the vectors $\mathbf{z}_{\mathrm{i}}$ solving the equation

$$
\mathbf{z}_{\mathbf{i}}^{T}\left(\mathbf{K}-\lambda_{\mathbf{i}} \mathbf{M}\right) \mathbf{z}_{\mathbf{i}}=0
$$

The first six natural frequencies are presented in Table 4 together with the values extracted from the laboratory tests. The corresponding modes of vibrations are presented in Figure 16.

When the modes of vibration from the experimental modal analysis are compared, Figure 11, with the values from the FE simulation, Figure 16, it can be seen that they are in good agreement.

When the natural frequencies are compared, it can be seen that the agreement is fairly good. In Figure 17 the difference between the experimental and FE simulated

\begin{tabular}{|c|c|c|}
\hline & $\mathrm{f}_{2}=51.9 \mathrm{~Hz}$ & $\mathrm{f}_{3}=53.3 \mathrm{~Hz}$ \\
\hline & & \\
\hline$f_{1}=7.4 \mathrm{~Hz}$ & $f_{2}=51.9 \mathrm{~Hz}$ & $f_{3}=53.3 \mathrm{~Hz}$ \\
\hline $\mathrm{f}_{4}=97.2 \mathrm{~Hz}$ & $\mathrm{f}_{5}=97.8$ & $\mathrm{f}_{6}=111.0 \mathrm{~Hz}$ \\
\hline & & \\
\hline & & \\
\hline$f_{4}=97.2 \mathrm{~Hz}$ & $f_{5}=97.8 \mathrm{~Hz}$ & $f_{6}=111.0 \mathrm{~Hz}$ \\
\hline
\end{tabular}

Figure 16. The first six modes of vibration for an element with free-free boundary conditions. 


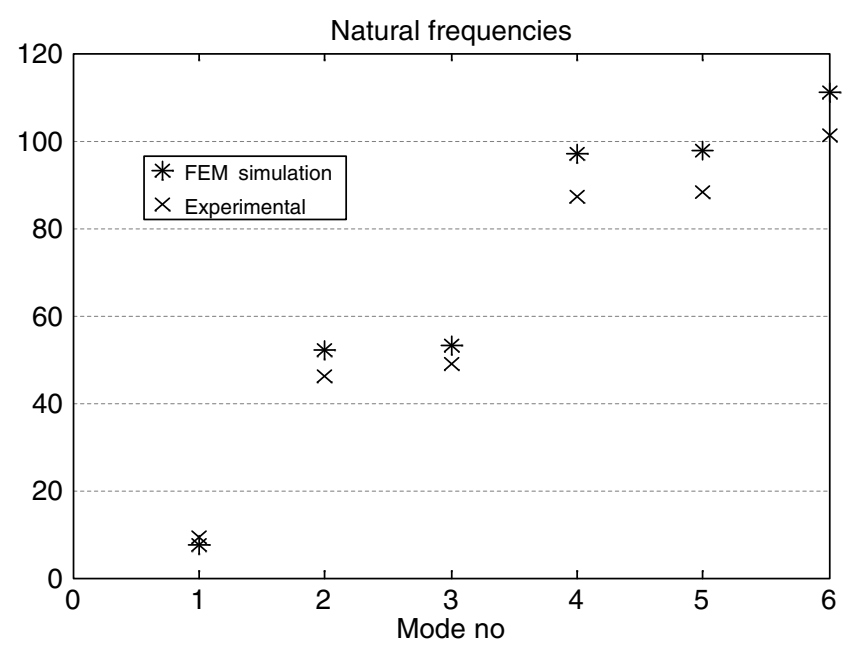

Figure 17. Experimental and FEM simulated natural frequencies.

frequencies are presented. The negative difference of the first natural frequency may be partly explained by the fact that supporting mattresses added stiffness to the system and thereby increase the natural frequency of the first mode.

To simulate a real structure, the FE model was used to investigate the natural frequencies and modes of vibration of a floor with $4.8 \mathrm{~m}$ span in the longitudinal bearing direction and $7 \mathrm{~m}$ wide in the transverse direction. The floor was assumed to be simply supported on all four edges and an evenly distributed load of $1 \mathrm{kN} / \mathrm{m}^{2}$, corresponding to a supposed added mass of false ceiling, flooring and live load, was added on the floor. The first six natural frequencies and modes of vibration are shown in Figure 18.

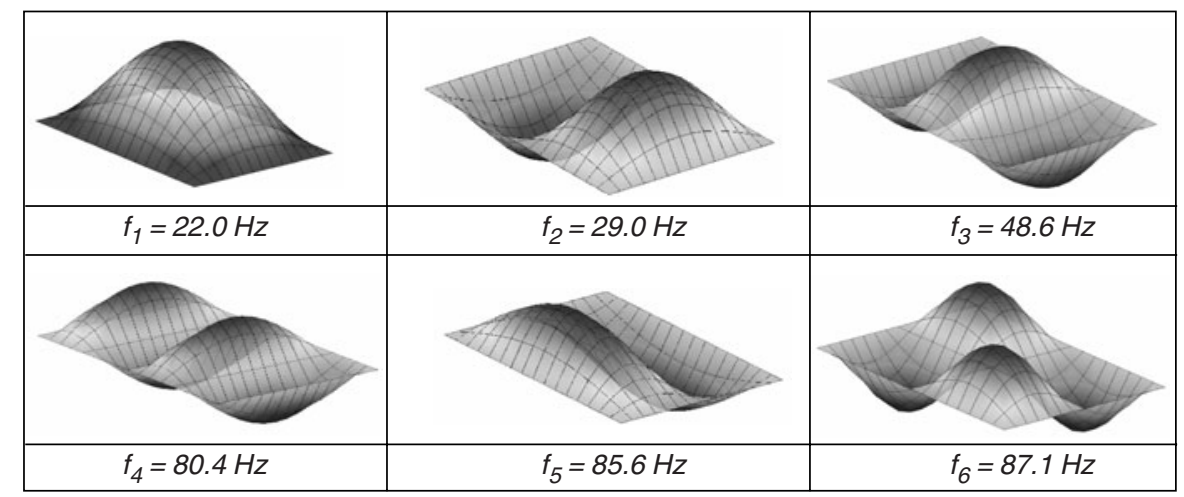

Figure 18. The first six modes of vibration of an on four edges simply supported floor. 
According to Olsson [5] the major force components in human steps are found at frequencies below $40 \mathrm{~Hz}$. In this example there are just two frequencies below $40 \mathrm{~Hz}$, and the first frequency also is fairly high, which will place the floor in the safer region given in the design directions in Swedish building regulations [6] and in EC5 [7].

\section{RESULTS AND DISCUSSION}

The natural frequencies and modes of vibration, according to the laboratory tests and FE calculations, were generally in good agreement. It is therefore concluded that the plate element model, representing stiffness simply by the parameters $D_{x}, D_{y}$ and $D_{x y}$, was sufficient for the analysis performed. The parameters $D_{x}$ and $D_{y}$, initially calculated using simple beam and bar element models, were only slightly modified when the results from a static laboratory test, load case 1, were employed for the final calibration of these parameters. The remaining stiffness parameter $D_{x y}$, representing torsional stiffness, was derived directly from a static laboratory test, load case 3 . The laboratory test results from load case 2 were not employed for calibration. Instead they were used for verification. A comparison of laboratory test results and deflections calculated by the FE model for load case 2 showed very good agreement.

Considering the relationship between the different stiffness parameters, it was found that the ratio $D_{y} / D_{x}$, i.e. the ratio between the bending stiffness in the main and transverse direction, was 0.26 . This is extremely high and was characteristic for the investigated floor. For traditional wooden floor systems the ratio is typically about 0.01 . The ratio $D_{x y} / D_{x}$ of 0.005 is in the same order as for traditional systems. An increase in the torsional stiffness would contribute significantly to increase the natural frequencies of the floor and thereby to the vibration performance.

Of the natural frequencies of the $2.4 \times 4.8 \mathrm{~m}$ test floor, under free-free conditions, only one frequency, representing a mode of pure torsion, was below $40 \mathrm{~Hz}$. The second natural frequency was $46 \mathrm{~Hz}$ according to the laboratory test and $52 \mathrm{~Hz}$ according to the FE calculation. A pure torsion mode will not appear in practical applications with realistic boundary conditions.

The major force components in human steps are at frequencies below $40 \mathrm{~Hz}$, and conventional wooden floors usually have several frequencies below $40 \mathrm{~Hz}$. As shown by the present paper, the investigated floor will have few natural frequencies below 40 $\mathrm{Hz}$ for realistic spans and boundary conditions. The lowest frequency will also be fairly high if pure torsion is prevented and thus place the floor in the safer region in the initial maximum velocity diagram given in the design directions in Swedish building regulations [6] and in EC5 [7]. In conclusion, the floor has the potential to perform well with respect to human-induced vibrations.

\section{FURTHER RESEARCH}

Further research and development of the floor system is being performed at Växjö University. In the next phase, an improved test floor is planned in which the transversely oriented wooden members will be replaced by thinwebbed beams of wood and hardboard, see Figure 19. 


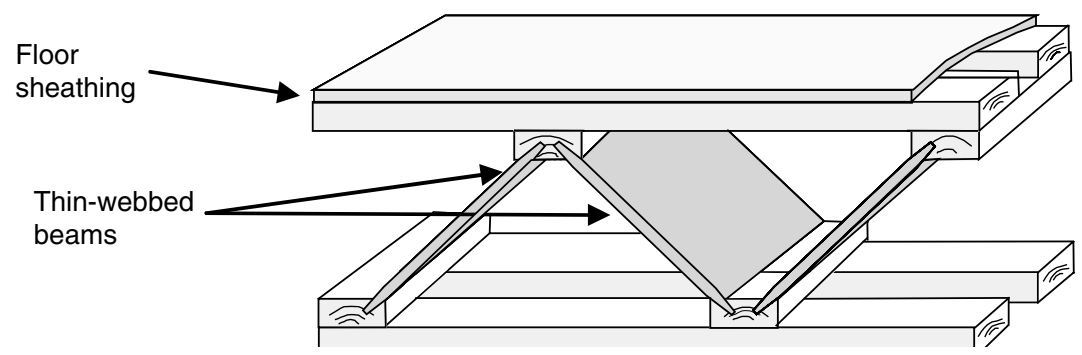

Figure 19. Proposed floor with thin-webbed beams of wood and hardboard.

The acoustic aspects will subsequently be considered and complementary ceiling or flooring designs developed. Other aspects to consider are the fire performance, production methods and the in-situ interlocking of elements.

\section{REFERENCES}

[1] Data Physics Corporation - Solutions in signal processing, Making Measurements with Mobylizer II, San Jose, 2002

[2] Axiom Edutech AB, Vibratools Suite ${ }^{\mathrm{TM}}$, Revision 6.4, Täby, Sweden, 2004

[3] The Mathwork, Inc., Matlab®, The Language of Technical Computing, Version 6.5, Release 13, 2002

[4] CALFEM - A Finite Element Toolbox, version 3.4, Structural Mechanics, LTH, Sweden, 2004

[5] S. Ohlsson, Floor vibrations and human discomfort, Doctoral thesis, Chalmers University of Technology, Gothenburg, Sweden, 1988

[6] S. Åkerlund, Vibrations, Indirect and Accidental Action, The National Board of Housing, Building and Planning, The Division of Building Construction, (Svängningar, deformationspåverkan och olyckslast, Boverket, byggavdelningen), Kristianstad, Sweden, 1994

[7] BS EN 1995-1-1:2004 Eurocode 5. Design of timber structures. General. Common rules and rules for buildings. 